\title{
Anion-mediated electronic effects in reducible oxides: Tuning the valence band of ceria via fluorine doping ${ }^{\circledR}$
}

Cite as: J. Chem. Phys. 151, 044701 (2019); https://doi.org/10.1063/1.5109955

Submitted: 14 May 2019 . Accepted: 13 June 2019 . Published Online: 22 July 2019

Miroslav Kettner (D), Tomáš Duchoň ${ }^{(D)}$, Matthew J. Wolf (D), Jolla Kullgren (D), Sanjaya D. Senanayake (D), Kersti Hermansson (D), Kateřina Veltruská (D), and Václav Nehasil (D)

\section{COLLECTIONS}

EP This paper was selected as an Editor's Pick
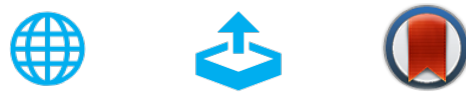

\section{ARTICLES YOU MAY BE INTERESTED IN}

Density functional analysis of atomic force microscopy in a dense fluid

The Journal of Chemical Physics 151, 034701 (2019); https://doi.org/10.1063/1.5110366

Counting quantum jumps: A summary and comparison of fixed-time and fluctuating-time statistics in electron transport

The Journal of Chemical Physics 151, 034107 (2019); https://doi.org/10.1063/1.5108518

Near-threshold photodissociation of $\mathrm{cool} \mathrm{OH}^{+}$to $\mathrm{O}+\mathrm{H}^{+}$and $\mathrm{O}^{+}+\mathrm{H}$

The Journal of Chemical Physics 151, 044303 (2019); https://doi.org/10.1063/1.5098321

The Journal

Submit Today

of Chemical Physics

The Emerging Investigators Special Collection and Awards Recognizing the excellent work of early career researchers! 


\title{
Anion-mediated electronic effects in reducible oxides: Tuning the valence band of ceria via fluorine doping
}

\author{
Cite as: J. Chem. Phys. 151, 044701 (2019); doi: 10.1063/1.5109955 \\ Submitted: 14 May 2019 - Accepted: 13 June 2019• \\ Published Online: 22 July 2019
}

\begin{abstract}
Miroslav Kettner, ${ }^{1,2, a), b)}$ (D) Tomáš Duchoň, ${ }^{1,3, a), c)}$ (D) Matthew J. Wolf,,
Sanjaya D. Senanayake, ${ }^{6}$ (D) Kersti Hermansson, ${ }^{4}$ (D) Kateřina Veltruská, ${ }^{\text {(D) }}$ and Václav Nehasil ${ }^{7}$
\end{abstract}

\section{AFFILIATIONS}

${ }^{1}$ Department of Surface and Plasma Science, Faculty of Mathematics and Physics, Charles University, V Holešovičkách 2 , 18000 Prague 8, Czech Republic

${ }^{2}$ Chair of Interface Research and Catalysis, Friedrich-Alexander-Universität Erlangen-Nürnberg, Egerlandstrasse 3 , 91058 Erlangen, Germany

${ }^{3}$ Peter-Grünberg-Institut 6, Forschungszentrum Jülich, 52425 Jülich, Germany

4Department of Chemistry-Ångström Laboratory, Uppsala University, Box 538, 75121 Uppsala, Sweden

${ }^{5}$ Department of Physics, University of Bath, Bath BA2 7AY, United Kingdom

${ }^{6}$ Department of Chemistry, Brookhaven National Laboratory, Upton, New York 11973, USA

a) Contributions: M. Kettner, T. Duchoň, and M. J. Wolf contributed equally to this work.

b) Electronic mail: mira.kettner@fau.de

${ }^{c)}$ Electronic mail: duchon@micronano.net

\begin{abstract}
Combining experimental spectroscopy and hybrid density functional theory calculations, we show that the incorporation of fluoride ions into a prototypical reducible oxide surface, namely, ceria(111), can induce a variety of nontrivial changes to the local electronic structure, beyond the expected increase in the number of $\mathrm{Ce}^{3+}$ ions. Our resonant photoemission spectroscopy results reveal new states above, within, and below the valence band, which are unique to the presence of fluoride ions at the surface. With the help of hybrid density functional calculations, we show that the different states arise from fluoride ions in different atomic layers in the near surface region. In particular, we identify a structure in which a fluoride ion substitutes for an oxygen ion at the surface, with a second fluoride ion on top of a surface Ce $\mathrm{e}^{4+}$ ion giving rise to $\mathrm{F} 2 \mathrm{p}$ states which overlap the top of the $\mathrm{O} 2 \mathrm{p}$ band. The nature of this adsorbate $\mathrm{F}^{-}-\mathrm{Ce}^{4+}$ resonant enhancement feature suggests that this bond is at least partially covalent. Our results demonstrate the versatility of anion doping as a potential means of tuning the valence band electronic structure of ceria.
\end{abstract}

Published under license by AIP Publishing. https://doi.org/10.1063/1.5109955

\section{INTRODUCTION}

Cation dopants are commonly used to tailor the (heterogeneous) catalytic activity and selectivity of reducible oxides, via the concerted changes to the electronic structure, morphology, and metal-support interactions that they induce. ${ }^{1-3}$ In contrast, anions (such as pnictides or halides) are seldom considered as dopants, even though anion-mediated reactivity is known to be common in other types of catalytic reactions, such as those in homogeneous organometallic catalysis. ${ }^{4,5}$ We believe that this is due, at least in part, to a lack of understanding of the effects of such dopants on the physicochemical properties of reducible oxides. The resulting imbalance is perhaps best illustrated by the case of the prototypical reducible oxide $\mathrm{CeO}_{2}$ (ceria), which has become a mainstay in catalytic applications in which oxygen buffering is essential. 
Current research in ceria based catalysis is almost entirely oriented toward investigating the effects of metal-supported oxides $\left(\mathrm{M}-\mathrm{CeO}_{x}\right)$, mixed oxides $\left(\mathrm{MO}_{x}-\mathrm{CeO}_{x}\right)$, and promoters $\left(\mathrm{P}-\mathrm{CeO}_{x}\right)$ (often involving foreign cations) on the reducibility, conductivity, and oxygen storage capacity of the host material. ${ }^{7}$ The wealth of literature that addresses changes to the properties of ceria induced by foreign cations is in stark contrast to the sparsity of studies treating anion impurities, with examples of the latter being mostly reports of contamination, ${ }^{8-11}$ rather than controlled doping. Motivated by recent works highlighting the role of anion-derived states of the valence band in catalytic reactions, ${ }^{12-15}$ we explore herein the viability of anion doping as a means of tailoring the electronic structure of ceria-based catalysts.

In this work, we focus on fluoride, a strongly electronegative halide anion with an almost identical ionic radius to the oxide anion. This choice of anion dopant is motivated by the fact that $\mathrm{CeOF}$ is known to be a stable material with very similar structural properties to ceria, ${ }^{16-18}$ suggesting that various levels of fluorine incorporation could be achieved with minimal disruption to the structure of the host lattice. This suggestion is supported by the results of theoretical calculations, ${ }^{19}$ as well as by the observation that exposing $\mathrm{CeO}_{2}$ to $\mathrm{F}_{2}$ gas above $130^{\circ} \mathrm{C}$ leads to fluorine incorporation without any change to the cubic structure, up to the conversion to the hexagonal $\mathrm{CeF}_{3}$ phase around $270{ }^{\circ} \mathrm{C} .{ }^{20}$ Furthermore, it has also been shown that fluorine can be incorporated into ceria on contact with fluorine-containing materials, such as Nafion ${ }^{\star}$ or $\mathrm{CaF}_{2} \cdot{ }^{9,21,22}$ Even commercially available ceria single crystals have been found to be contaminated with fluorine, although the origin of the contamination is unclear. ${ }^{11}$ Importantly, experiments on the contaminated single crystals reveal that fluorine tends to accumulate close to the surface, with a gradient decreasing into the bulk. We note that catalytic processes and associated phenomena (e.g., metal-support interaction) are governed by surface properties. Considering the broad range of possibilities for (unintentional) fluorine incorporation into ceria, knowledge of its effects on the properties of the material is severely lacking, and there is no indication as to whether fluorination should be prevented or encouraged for specific applications.

Fluorine is incorporated into bulk ceria in the form of $\mathrm{F}^{-}$ions substituting for lattice $\mathrm{O}^{2-}$ ions. The most obvious electronic effect of this substitution is the addition to the system of one electron per fluoride ion; the excess electron localizes in a $4 \mathrm{f}$ orbital of a single $\mathrm{Ce}$ ion, reducing the nominal oxidation state of the ion from $4+$ to $3+{ }^{19,22,23}$ As we have shown previously, the $\mathrm{Ce}^{3+}$ ion associated with an $\mathrm{F}^{-}$substituent is not spectroscopically identical to that in pure ceria, as is directly evident from Ce $3 \mathrm{~d}$ core-level photoemission spectra, where both the ratio and position of the final state components differ. ${ }^{22}$ A careful deconvolution of the Ce $3 \mathrm{~d}$ spectra can isolate the $\mathrm{Ce}^{3+}-\mathrm{F}$ interaction components and utilize the difference for the determination of the extent of fluorination of the sample. The presence of characteristic $\mathrm{Ce}^{3+}-\mathrm{F}$ interaction components in the Ce $3 \mathrm{~d}$ spectra also implies a distinct screening response to the $3 \mathrm{~d}$ core hole. ${ }^{24-26}$ The specific properties of the $\mathrm{Ce}^{3+}$ ions associated with fluorine defects are important because of the significant role that $4 \mathrm{f}$ electrons play in ceria-related chemistry. ${ }^{27}$ It is therefore conceivable that fluorine-doped ceria $\left(\mathrm{Ce}^{3+}-\mathrm{F}\right)$ and reduced ceria $\left(\mathrm{CE}^{3+}\right.$-vacancy) will behave differently with respect to phenomena such as charge transfer, metal-support interaction, or oxygen storage capacity. However, we have already shown that in the limit of low concentration fluorine doping presents a relatively stable way for changing the oxidation state of ceria without hampering its oxygen storage capacity. ${ }^{28}$

The examples above indicate that the effect of incorporation of fluorine into ceria extends beyond simply increasing the number of $4 \mathrm{f}$ electrons. Of particular interest is the extent to which fluorine- and cerium-derived states mix. In undoped ceria, covalent interactions of $\mathrm{O} 2 \mathrm{p}$ and Ce $5 \mathrm{~d}$ and $4 \mathrm{f}$ states, which constitute a major part of the valence band, ${ }^{29}$ are important with respect to properties such as reducibility. ${ }^{30}$ Mixing of F $2 \mathrm{p}$ and Ce $5 \mathrm{~d}$ and $4 \mathrm{f}$ states can be expected to lead to the modification of the density of states outside of the $\mathrm{O} 2 \mathrm{p}$ band. Such modifications could enhance the alignment with several relevant molecules at energies below the $\mathrm{O} 2 \mathrm{p}$ band, such as water (characteristic $1 \mathrm{~b}_{1}$ and $3 \mathrm{a}_{1}$ states at $6.9 \mathrm{eV}$ and $9.5 \mathrm{eV}$, respectively), methanol, ethanol, and $\mathrm{OH}^{-}$( $3 \sigma$ orbitals at $9.8 \mathrm{eV}) .{ }^{31-33}$ On the other hand, states at energies above the $\mathrm{O} 2 \mathrm{p}$ band offer possibilities for altering the interaction with $\mathrm{d}$ states of metals that are commonly supported on ceria, such as $\mathrm{Cu}, \mathrm{Ni}$, and $\mathrm{Pt}^{34,35}$ We further note that the alignment of electron bands has a wide impact on charge transfer properties both at the surface and interface of metal oxide materials.

In order to explore the effects of fluorine incorporation on the electronic structure of cation-undoped ceria, here, we utilize resonant photoemission spectroscopy (RPES) at the Ce $4 \mathrm{~d} \rightarrow \mathrm{Ce} 4 \mathrm{f}$ photoabsorption threshold. RPES is conducted via tuning the primary photon energy so as to induce a constructive interference of electrons generated by a direct photoemission process and those generated via an Auger decay. We have previously shown that the resonant photoemission process in (nominally) pure ceria depends on the (initial) charge state of the photoionized cation in the following way:

For a $\mathrm{Ce}^{3+}$ ion, it is an intra-atomic process that greatly enhances the spectral gain from 4 f electrons, allowing detection of such species when present even in very small concentrations,

$$
\begin{aligned}
\mathrm{Ce} 4 \mathrm{~d}^{10} 4 \mathrm{f}^{1} \mathrm{O} 2 \mathrm{p}^{6}+h v & \rightarrow \operatorname{Ce} 4 \mathrm{~d}^{9} 4 \mathrm{f}^{2} \mathrm{O} 2 \mathrm{p}^{6} \\
& \rightarrow \operatorname{Ce} 4 \mathrm{~d}^{10} 4 \mathrm{f}^{0} \mathrm{O} 2 \mathrm{p}^{6}+\mathrm{e}^{-} .
\end{aligned}
$$

For a $\mathrm{Ce}^{4+}$ ion, in contrast, it is an inter-atomic process that carries information about cation-anion covalency,

$$
\begin{aligned}
\mathrm{Ce} 4 \mathrm{~d}^{10} 4 \mathrm{f}^{0} \mathrm{O} 2 \mathrm{p}^{6}+h v & \rightarrow \mathrm{Ce} 4 \mathrm{~d}^{9} 4 \mathrm{f}^{1} \text { O } 2 \mathrm{p}^{6} \\
& \rightarrow \operatorname{Ce} 4 \mathrm{~d}^{10} 4 \mathrm{f}^{0} \text { O } 2 \mathrm{p}^{5}+\mathrm{e}^{-} .
\end{aligned}
$$

As such, RPES allowed us to directly demonstrate that the resonant enhancement of $\mathrm{Ce}^{4+}$ is brought about by covalent interaction of the $\mathrm{Ce} 4 \mathrm{f}$ and $\mathrm{O} 2 \mathrm{p}$ states, indicating a partially covalent character of the $\mathrm{Ce}-\mathrm{O}$ bond.

In addition to the results obtained with RPES, we use the results of hybrid density functional theory calculations to link the measured electronic structure with the atomic scale structure of the surface. We show how the fluorine contribution to the valence band changes in relation to its depth distribution and identify a specific configuration of fluoride ions bonded to $\mathrm{Ce}^{4+}$ at the surface that gives rise to an F $2 p$ band which is shifted toward the top of the O $2 p$ band and exhibits an appreciable degree of covalency. Our results indicate that doping with fluorine represents a straightforward and flexible 
method for altering the density of states in ceria above, within, and below the $\mathrm{O} 2 \mathrm{p}$ band.

\section{EXPERIMENTAL AND THEORETICAL METHODS}

Resonant photoemission spectroscopy experiments were conducted in an ultrahigh vacuum system at the Materials Science Beamline at Synchrotron Elettra (Trieste, Italy). The system has a base pressure of $1 \times 10^{-8} \mathrm{~Pa}$ and features LEED optics, a dual $\mathrm{Mg} / \mathrm{Al}$ anode X-ray source, and electron energy analyzer (SPECS Phoibos 150), in addition to sample cleaning and preparation facilities. The substrate used was a $\mathrm{Rh}(111)$ single crystal (MaTecK), which was first cleaned by $\mathrm{Ar}^{+}$sputtering and annealing in $1 \times 10^{-5} \mathrm{~Pa}$ of $\mathrm{O}_{2}$ (Linde 4.5) to $700{ }^{\circ} \mathrm{C}$ followed by a brief flash annealing to $900^{\circ} \mathrm{C}$. Ce (Goodfellow) was evaporated from tantalum crucibles heated by electron bombardment for the growth of undoped samples. Fluorine-doped samples were prepared utilizing a separate evaporator of the same construction which was loaded with Ce (Alfa Aesar 99.9\%) that had been pre-exposed to HF vapor for $60 \mathrm{~min}$ at $90{ }^{\circ} \mathrm{C}$. Detailed description of the growth process follows in the next paragraph. The as-prepared films were checked by LEED for the characteristic hexagonal diffraction pattern of the (111) surface termination of ceria layers. The prepared layers were continuous, i.e., no Rh(111) LEED spots were observed. Detailed information on the growth, ordering, and morphology of fluorine-doped ceria on $\mathrm{Rh}(111)$ can be found in our previous paper. ${ }^{28}$ Briefly, the fluorine-doped ceria shows elongated LEED spots due to a $9^{\circ}$ rotation with respect to the $\mathrm{Rh}(111)$ substrate; the structure is cubic with (111) surface termination. The thickness of the films was determined to be $\sim 9 \mathrm{ML}$ from the attenuation of the Rh $3 d$ signal, using TPP-2M for the inelastic mean free path in ceria as implemented in QUASES-IMFP-TPP2M.

Two samples containing dominantly $\mathrm{Ce}^{3+}$ ions were prepared by cerium deposition in an ultrahigh vacuum $\left(\mathrm{c}-\mathrm{Ce}_{2}^{3+} \mathrm{O}_{3}^{2-}\right.$ and $\mathrm{Ce}_{0.07}^{4+} \mathrm{Ce}_{0.93}^{3+} \mathrm{O}_{1.06}^{2-} \mathrm{F}_{0.88}^{-}$). The absence of oxygen during the deposition is guided by our previous experience with the apparatus (including outgassing of the source material) that takes into account cerium metal acting as an excellent getter for oxygen-containing species in the rest atmosphere (i.e., water) and adsorbates on the surface (oxygen left from cleaning procedures). The rest of the samples $\left(\mathrm{Ce}_{0.55}^{4+} \mathrm{Ce}_{0.45}^{3+} \mathrm{O}_{1.37}^{2-} \mathrm{F}_{0.80}^{-}, \mathrm{Ce}_{0.73}^{4+} \mathrm{Ce}_{0.27}^{3+} \mathrm{O}_{1.87}^{2-}\right.$, and $\left.\mathrm{Ce}_{0.97}^{4+} \mathrm{Ce}_{0.03}^{3+} \mathrm{O}_{1.99}^{2-}\right)$ were grown in the reactive atmosphere of $5 \times 10^{-5} \mathrm{~Pa}$ of $\mathrm{O}_{2}$ (Linde 4.5). The fluorine content in the sample of intermediate stoichiometry was controlled by alternating deposition of fluorine-doped and undoped ceria in several steps. All the samples were grown at room temperature and afterward annealed to $250^{\circ} \mathrm{C}$. Postpreparation: the stoichiometry of the samples was finely adjusted by exposure to either $\mathrm{O}_{2}$ or $\mathrm{H}_{2}$ at $250{ }^{\circ} \mathrm{C}$ in order to match the stoichiometry of the fluorine-doped and pure cerium samples as closely as possible. Two of the samples $\left(\mathrm{Ce}_{0.07}^{4+} \mathrm{Ce}_{0.93}^{3+} \mathrm{O}_{1.06}^{2-} \mathrm{F}_{0.88}^{-}\right.$and $\left.\mathrm{Ce}_{0.73}^{4+} \mathrm{Ce}_{0.27}^{3+} \mathrm{O}_{1.87}^{2-}\right)$ were flashed to $800^{\circ} \mathrm{C}$ in order to further adjust the sample stoichiometry while making sure via LEED that the ordering and continuity are not affected.

Photoemission spectroscopy of the Ce 3d, F 1s, O 1s, C 1s, and $\mathrm{Rh} 3 \mathrm{~d}$ core levels was performed with $\mathrm{X}$-ray radiation of $1253.6 \mathrm{eV}$ $(\mathrm{Mg} \mathrm{K} \alpha)$, and valence band spectra were measured with synchrotron radiation in the range of $115-125 \mathrm{eV}$. No charging effects were observed in the photoemission spectra, and the samples showed no or only minor carbon contamination. The presented Ce $3 \mathrm{~d}$ spectra have been processed in order to remove the X-ray satellite peaks using procedures implemented in CasaXPS and then deconvoluted into $\mathrm{Ce}^{4+}, \mathrm{Ce}^{3+}$, and $\mathrm{Ce}-\mathrm{F}$ doublets. The expected deviation of this deconvolution procedure is of the order of a few percent. Detailed parameters of the deconvolution procedure can be found in Ref. 22.

The stoichiometry of the samples was determined from the $\mathrm{Ce}^{4+} / \mathrm{Ce}^{3+}$ and $\mathrm{O} 1 \mathrm{~s} / \mathrm{F} 1 \mathrm{~s}$ area ratios according to the charge neutrality principle. In the case of fluorine-free samples $\left(\mathrm{CeO}_{x}\right)$, this calculation is reduced to the equation

$$
x=1.5+0.5 \frac{\mathrm{Ce}^{4+}}{\mathrm{Ce}_{\text {tot }}}
$$

where $\mathrm{Ce}^{4+}$ and $\mathrm{Ce}_{\text {tot }}$ are the areas of $\mathrm{Ce}^{4+}$ doublets and total Ce $3 \mathrm{~d}$ area, respectively. However, to get the $x$ and $y$ values in the case of fluorine-doped samples $\left(\mathrm{CeO}_{x} \mathrm{~F}_{y}\right)$, we combine the following two equations:

$$
4 \frac{\mathrm{Ce}^{4+}}{\mathrm{Ce}_{\mathrm{tot}}}+3 \frac{\mathrm{Ce}^{3+}}{\mathrm{Ce}_{\mathrm{tot}}}=2 x+y
$$

and

$$
\frac{\mathrm{O} 1 \mathrm{~s}}{\mathrm{~F} 1 \mathrm{~s}}=\frac{x}{y}
$$

where $\mathrm{Ce}^{3+}$ is the area of $\mathrm{Ce}^{3+}$ doublets, and $\mathrm{O} 1 \mathrm{~s}$ and $\mathrm{F} 1 \mathrm{~s}$ are the areas of $\mathrm{O} 1 \mathrm{~s}$ and $\mathrm{F} 1 \mathrm{~s}$ peaks corrected with XPS sensitivity factors, respectively. ${ }^{40}$ The stoichiometry calculations are carried out in the approximation of a homogeneous distribution of the respective elements. The $\mathrm{Ce}-\mathrm{F}$ area is considered as containing $\mathrm{Ce}^{3+}$ ions only because it is directly derived from the spectrum of $\mathrm{CeF}_{3}$.

Density functional theory calculations were carried out using the projector augmented wave (PAW) method, ${ }^{41}$ as implemented in the Vienna Ab initio Simulation Package (VASP), version 5.3.5. ${ }^{42-45}$ We used the standard Perdew-Burke-Ernzerhof (PBE) potentials distributed with this version of VASP, which incorporate the [Xe] $4 \mathrm{~d}$ electrons of $\mathrm{Ce}$ atoms and the $1 \mathrm{~s}$ electrons of $\mathrm{O}$ and $\mathrm{F}$ atoms into the cores, with a plane-wave cutoff energy of $400 \mathrm{eV}$, and a $4 \times 4$ $\times 1$, $\Gamma$ centred $k$-point mesh which was generated according to the Monkhorst-Pack scheme. ${ }^{46}$ The structural model comprised a slab of 12 atomic layers (for the stoichiometric slab), with a $\mathrm{p}(1 \times 1)$ surface unit cell, and a vacuum gap corresponding to 15 atomic layers of bulk ceria. The addition of fluorine to the slab was performed symmetrically with respect to the top and bottom surfaces in order to avoid the formation of a dipole across it.

We employed the HSE06 screened hybrid functional for our calculations. ${ }^{47,48}$ While HSE06 has been shown to overestimate the band gap of ceria and underestimate the reduction energy, ${ }^{49,50}$ it describes very well the lattice parameter and width of the valence band. ${ }^{29}$ Since we are interested primarily in the relationship between structure and occupied electronic states in our study, we expect it to be fit for our purposes.

The projected densities of states were generated by calculating the contributions of the atoms to the Kohn-Sham eigenstates using the projectors associated with the PAW potentials, and then convolving the resulting spectra with Gaussian functions with standard deviations of $0.1 \mathrm{eV}$ in energy and $0.1 \AA$ in space. We note that the 
projector functions used for such an analysis are arbitrary to some extent and that, therefore, the results should be viewed as being qualitative rather than quantitative.

\section{RESULTS AND DISCUSSION}

\section{A. Experimental results}

In order to fully utilize the advantage of RPES in this comparative study, we prepared five samples with similar structures but different compositions. Three reference, fluorine-free, samples were prepared containing $\mathrm{Ce}^{3+}$ ions only, a mixture of $\mathrm{Ce}^{3+}$ and $\mathrm{Ce}^{4+}$ ions, and mainly $\mathrm{Ce}^{4+}$ ions. The stoichiometry of the prepared samples was evaluated according to Eq. (1), and these samples will be referred to as $\mathrm{c}-\mathrm{Ce}_{2}^{3+} \mathrm{O}_{3}^{2-}, \mathrm{Ce}_{0.73}^{4+} \mathrm{Ce}_{0.27}^{3+} \mathrm{O}_{1.87}^{2-}$, and $\mathrm{Ce}_{0.97}^{4+} \mathrm{Ce}_{0.03}^{3+} \mathrm{O}_{1.99}^{2-}$, respectively. We compare those to two fluorine-doped samples containing only $\mathrm{Ce}^{3+}$ ions and a mixture of $\mathrm{Ce}^{3+}$ and $\mathrm{Ce}^{4+}$ ions. Using Eqs. (2) and (3), the stoichiometry of these fluorine-doped samples was evaluated to be $\mathrm{Ce}_{0.07}^{4+} \mathrm{Ce}_{0.93}^{3+} \mathrm{O}_{1.06}^{2-} \mathrm{F}_{0.88}^{-}$and $\mathrm{Ce}_{0.55}^{4+} \mathrm{Ce}_{0.45}^{3+} \mathrm{O}_{1.37}^{2-} \mathrm{F}_{0.80}^{-}$. We note that, disregarding any unusual methods, it is not possible to prepare a fluorine-doped sample containing only $\mathrm{Ce}^{4+}$ ions.

The Ce 3d XPS spectra of the samples are shown in Figs. 1(a)-1(e). The spectra were deconvolved into $\mathrm{Ce}^{3+}$ (blue), $\mathrm{Ce}^{4+}$ (green), and Ce-F (orange) components according to procedures described in detail in Ref. 22. Because the Ce $3 \mathrm{~d}$ spectrum has been the subject of many previous studies, we refer the reader to Refs. 7 and 24 and references therein for further details regarding its shape and deconvolution. In Fig. 1(a), we see a typical Ce 3d spectrum of a ceria sample containing solely $\mathrm{Ce}^{3+}$ ions. This spectrum can be compared to a fluorine-doped sample also containing predominantly $\mathrm{Ce}^{3+}$ ions [Fig. 1(b)]. We observe that in Fig. 1(b) both the ratio of and gap between the measured components are altered as a result of the appearance of fluorine related spectral features. In Figs. 1(c) and 1(d), we can compare the spectra of fluorine-doped and fluorine-free samples of intermediate stoichiometry, respectively. Here, the shapes of the spectra are dominated by the $\mathrm{Ce}^{4+}$ components; however, the changes in spectral shape between $\mathrm{Ce}_{0.55}^{4+} \mathrm{Ce}_{0.45}^{3+} \mathrm{O}_{1.37}^{2-} \mathrm{F}_{0.80}^{-}$and $\mathrm{Ce}_{0.73}^{4+} \mathrm{Ce}_{0.27}^{3+} \mathrm{O}_{1.87}^{2-}$ samples identifying the presence of fluorine are still clearly visible. For comparison, in Fig. 1(e), the Ce $3 \mathrm{~d}$ spectrum consisting mainly of $\mathrm{Ce}^{4+}$ doublets is shown.

The measured RPES spectra are shown in the right-hand column of Fig. 1. The RPES was acquired immediately after the XPS measurement and thus corresponds directly to the state of the sample as described by the XPS spectra discussed above. The resonant photoemission spectra at the $\mathrm{Ce} 4 \mathrm{~d} \rightarrow \mathrm{Ce} 4 \mathrm{f}$ photoabsorption threshold are measured at three different photon energies, 115, 121.4, and $124.8 \mathrm{eV}$, shown in Figs. 1(f)-1(j) as black, red, and green curves, respectively. The energy of $115 \mathrm{eV}$ is the so-called off-resonance energy, which is below the photoabsorption threshold. Tuning the energy to $121.4 \mathrm{eV}$ induces a resonant enhancement of the $4 \mathrm{f}$ state [ 1.7 eV, see the red line in Fig. 1(f)], which is exclusively due to the $\mathrm{Ce}^{3+}$ ions. On the other hand, tuning the energy to $124.8 \mathrm{eV}$ induces a resonant enhancement of the top of the $\mathrm{O} 2 \mathrm{p}$ band $[\sim 3.6 \mathrm{eV}$, see the green line in Fig. 1(j)], which is indicative of the contribution of the $\mathrm{Ce}^{4+}$ ions to those states. ${ }^{37,51}$ It is important to note that the resonant enhancement follows a Fano-type profile, with a sharp rise in intensity below the absorption threshold and a

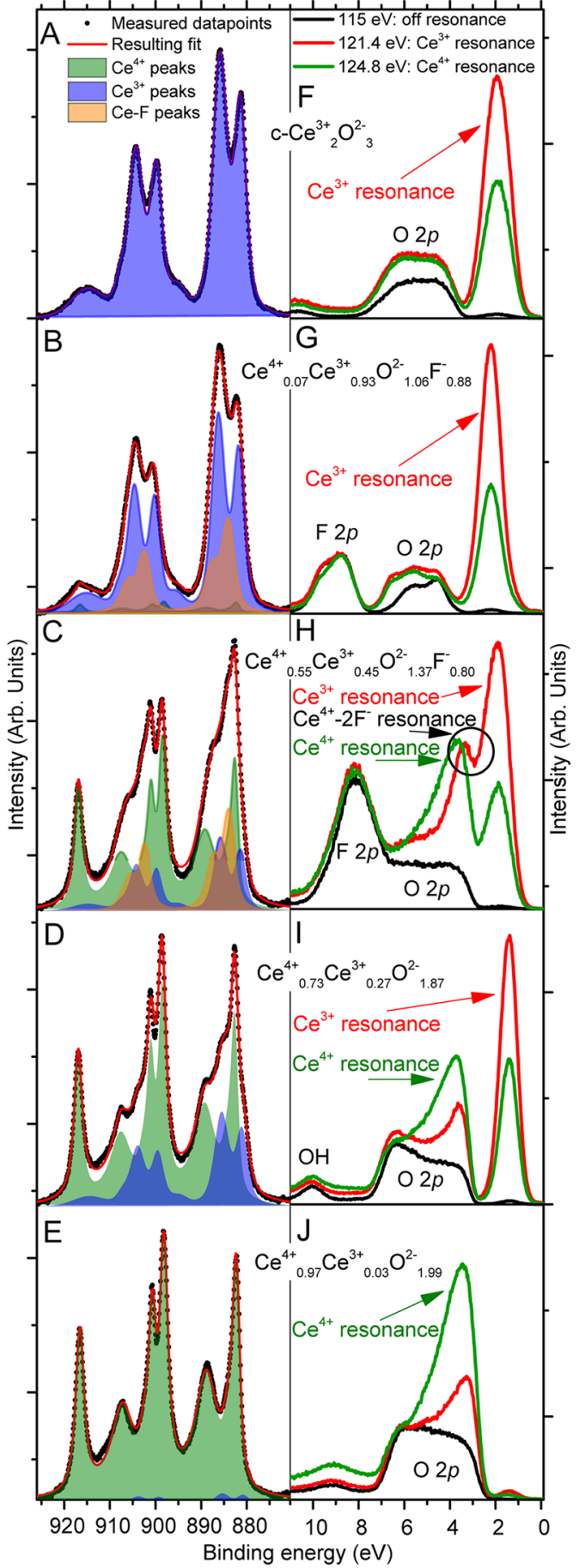

FIG. 1. Photoemission analysis of the fluorine-free and fluorine-doped ceria samples. All spectra are normalized to the maximum intensity. [(a)-(e)] Ce $3 \mathrm{~d}$ corelevel spectra acquired with a primary photon energy of $1253.6 \mathrm{eV}$. The spectra show components resulting from the deconvolution procedure that was used to determine the stoichiometry of the respective samples. [(f)-(j)] Resonant photoemission spectroscopy of the corresponding samples carried out at the Ce $4 \mathrm{~d}$ $\rightarrow \mathrm{Ce} 4 \mathrm{f}$ photoabsorption threshold. The resonant features are indicated with arrows. 
more gradual decrease in intensity above the absorption threshold. Consequently, we are able to observe a slight enhancement of $\mathrm{Ce}^{4+}$ features, when the energy is tuned to the $\mathrm{Ce}^{3+}$ resonance maximum $(121.4 \mathrm{eV})$, and, vice versa, the $\mathrm{Ce}^{3+}$ features are also enhanced at the $\mathrm{Ce}^{4+}$ resonance energy $(124.8 \mathrm{eV})$ [see resonant enhancements in ceria of intermediate stoichiometry - Fig. 1(i)]. Our previous work on the subject contains a comprehensive explanation of the resonant photoemission enhancement at the Ce $4 \mathrm{~d} \rightarrow$ Ce $4 \mathrm{f}$ photoabsorption threshold. ${ }^{37}$ For further details regarding the $\mathrm{Ce} 4 \mathrm{~d} \rightarrow \mathrm{Ce} 4 \mathrm{f}$ resonant enhancement in ceria, we refer the reader to this work.

We begin the discussion of the RPES spectra by comparing the samples containing virtually only $\mathrm{Ce}^{3+}$ ions, viz., $\mathrm{Ce}_{0.07}^{4+} \mathrm{Ce}_{0.93}^{3+} \mathrm{O}_{1.06}^{2-} \mathrm{F}_{0.88}^{-}$and $\mathrm{c}-\mathrm{Ce}_{2}^{3+} \mathrm{O}_{3}^{2-}$, which are shown in Figs. $1(\mathrm{f})$ and $1(\mathrm{~g})$, respectively. The $\mathrm{c}-\mathrm{Ce}_{2}^{3+} \mathrm{O}_{3}^{2-}$ spectrum consists of two principal features, which are due to occupied $\mathrm{Ce} 4 \mathrm{f}$ and $\mathrm{O} 2 \mathrm{p}$ states at $\sim 1.7 \mathrm{eV}$ and 3-7 eV, respectively. The most striking difference in the $\mathrm{Ce}_{0.07}^{4+} \mathrm{Ce}_{0.93}^{3+} \mathrm{O}_{1.06}^{2-} \mathrm{F}_{0.88}^{-}$spectrum compared to that of $\mathrm{c}-\mathrm{Ce}_{2}^{3+} \mathrm{O}_{3}^{2-}$ is a broad new feature consisting of two contributions at $8.6 \mathrm{eV}$ and $9.5 \mathrm{eV}$, which we ascribe to $\mathrm{F} 2 \mathrm{p}$ states. We also note a slight alteration of the $\mathrm{O} 2 \mathrm{p}$ spectral envelope, which we expect to be due to two effects: the substitutional fluorine incorporation (a) changes the relative number of $\mathrm{O} 2 \mathrm{p}$ states with respect to $\mathrm{c}-\mathrm{Ce}_{2}^{3+} \mathrm{O}_{3}^{2-}$ and (b) creates new coordination shells for oxygen ions. The latter effect will influence the electrostatic potential around the oxygen ions, and consequently the degree of covalency of the bond between $\mathrm{O} 2 \mathrm{p}$ and $\mathrm{Ce} 4 \mathrm{f}$ and Ce $5 \mathrm{~d}$ electrons. ${ }^{24-26}$ Nevertheless, we expect that the most significant effect on the chemistry will be provided by direct interaction with the $\mathrm{F} 2 \mathrm{p}$ electrons.

Surprisingly, the fluorine-doped sample of intermediate stoichiometry, $\mathrm{Ce}_{0.55}^{4+} \mathrm{Ce}_{0.45}^{3+} \mathrm{O}_{1.37}^{2-} \mathrm{F}_{0.80}^{-}$, presents a qualitatively different spectrum [see Fig. 1(h)] to that of the fully reduced sample. The previously observed F 2 p spectral features appear to be shifted toward lower binding energy and, possibly due to the overlap of several states, to form a broad envelope with its maximum at $8.2 \mathrm{eV}$. Interestingly, the shift leads to the conjoining of the $\mathrm{F} 2 \mathrm{p}$ and $\mathrm{O} 2 \mathrm{p}$ spectral envelopes. Even more remarkable is the modification of the density of states at the top of the $\mathrm{O} 2 \mathrm{p}$ band, which, while invisible using off-resonance photon energies, is revealed through the resonant photoemission process. Specifically, we see a new maximum at the $\mathrm{Ce} 4 \mathrm{~d} \rightarrow \mathrm{Ce} 4 \mathrm{f}$ photoabsorption threshold for $\mathrm{Ce}^{3+}$ ions $(121.4 \mathrm{eV})$ at a binding energy of $3.4 \mathrm{eV}$ [black circle in Fig. 1(h)]. This maximum is shifted by $0.25 \mathrm{eV}$ in comparison to the fluorine-free ceria sample of similar stoichiometry [see the results for $\mathrm{Ce}_{0.73}^{4+} \mathrm{Ce}_{0.27}^{3+} \mathrm{O}_{1.87}^{2-}$ in Fig. 1(i)]. We note that the regular $\mathrm{Ce}^{4+}$ resonant enhancement at $124.8 \mathrm{eV}$ has its peak at $3.6 \mathrm{eV}$ [see the green peak in Fig. 1(j)]. The small resonant enhancement at $\sim 1.7 \mathrm{eV}$ in red $121.4 \mathrm{eV}$ spectrum of Fig. $1(\mathrm{j})$ is caused by a minute reduction of the $\mathrm{Ce}_{0.97}^{4+} \mathrm{Ce}_{0.03}^{3+} \mathrm{O}_{1.99}^{2-}$ sample.

Concerning the differences in Figs. 1(h) and 1(i), the resonating $\mathrm{O} 2 \mathrm{p}$ states necessarily cannot have the same intensity at photon energies both below $(121.4 \mathrm{eV})$ and at $(124.8 \mathrm{eV})$ the $\mathrm{Ce} 4 \mathrm{~d}$ $\rightarrow$ Ce 4 f photoabsorption threshold for $\mathrm{Ce}^{4+}$ ions [see the red and green spectra in Fig. 1(h)]. Therefore, the shift of the maximum to $3.4 \mathrm{eV}$ observed for the fluorine-doped sample of intermediate stoichiometry $\left(\mathrm{Ce}_{0.55}^{4+} \mathrm{Ce}_{0.45}^{3+} \mathrm{O}_{1.37}^{2-} \mathrm{F}_{0.80}^{-}\right)$reveals the presence of new resonating states that are necessarily distinct from the resonating $\mathrm{O} 2 \mathrm{p}$ states in the fluorine-free sample. Interestingly, the new states must also include contributions from $\mathrm{Ce}^{4+}$ ions, which is emphasized by the fact that the presence of fluorine in ceria containing only $\mathrm{Ce}^{3+}$ ions does not lead to the same effect [compare red RPES spectra in Figs. 1(g) and 1(h)]. The observed divergence between the $\mathrm{Ce}^{4+}$ and $\mathrm{Ce}^{3+}$ ions is in line with recent theoretical ${ }^{26}$ and experimen$\mathrm{tal}^{37}$ examination of the cation-anion interactions in ceria, where the former is found to be more sensitive to the anion shell.

\section{B. Theoretical calculations}

In order to investigate the origin of the observed effects, we calculated the electronic structure of model fluorine-doped ceria(111) structures using hybrid density functional theory. We initially consider models containing fluoride substituents in the surface and subsurface oxygen layers of a (111) ceria slab. The corresponding calculated atom projected densities of states (PDOS) are shown in Figs. 2(a) and 2(b). In the model shown in Fig. 2(a), fluoride ions substitute for all the oxygen ions in the subsurface (third atomic) layer, as a consequence of which, all the surface cerium ions are $\mathrm{Ce}^{3+}$. The model in Fig. 2(b) also has $\mathrm{Ce}^{3+}$ ions at the surface; however, fluoride ions substitute for oxygen ions in the first surface layer. The PDOS are separated vertically in Figs. 2(a)-2(c). Each line of PDOS corresponds to the contribution from ions with which it is aligned in the structural model to the left of each plot. The binding energy is given with respect to the Fermi level, which is chosen to be approximately halfway between the occupied and unoccupied Ce $4 \mathrm{f}$ states, and does not necessarily correspond to the experimental one.

By using the vertically separated PDOS, we can easily ascribe the states to the ions from which they originate. Specifically, in Fig. 2(a), we observe that the subsurface fluoride ions give rise to a band at around $8 \mathrm{eV}$, separated from the broad $\mathrm{O} 2 \mathrm{p}$ band from $\sim 7$ to $\sim 3 \mathrm{eV}$, and the occupied $4 \mathrm{f}$ states of $\mathrm{Ce}^{3+}$ ions are located at $\sim 0.5 \mathrm{eV}$. Comparing the results in Figs. 2(a) and 2(b), we see that the $\mathrm{F} 2 \mathrm{p}$ states of the surface fluoride ion are at binding energies which are approximately $0.5 \mathrm{eV}$ lower than those of the subsurface fluoride ion. This results in the closing of the gap between the $\mathrm{F} 2 \mathrm{p}$ and $\mathrm{O}$ $2 p$ states apparent in Fig. 2(a). We recall that the measured valence band photoemission spectrum of $\mathrm{Ce}_{0.07}^{4+} \mathrm{Ce}_{0.93}^{3+} \mathrm{O}_{1.06}^{2-} \mathrm{F}_{0.88}^{-}$exhibits such a gap, while that of $\mathrm{Ce}_{0.55}^{4+} \mathrm{Ce}_{0.45}^{3+} \mathrm{O}_{1.37}^{2-} \mathrm{F}_{0.80}^{-}$does not. With this in mind, the computational results indicate that there is a different depth distribution of fluorine for the two samples. While theory predicts fluorine to be located primarily in the surface layer of a thermodynamically equilibrated ceria sample, ${ }^{19,23}$ this has been determined only for low levels of reduction. It is conceivable that the situation is different for ceria containing only $\mathrm{Ce}^{3+}$ ions. Severe reduction of ceria leads to the stabilization of ordered structures of oxygen vacancies in the surface, ${ }^{53}$ which could hinder the segregation of fluorine to the surface. Consequently, not only the concentration of fluorine but also the concentration of oxygen vacancies affects the depth distributions of fluorine in the sample, and therefore the binding energy of the F 2 p states.

The calculated density of states of the model in Fig. 2(a) shows another interesting effect, namely, that the $2 p$ states of the oxygen ions in the surface contract and shift to lower binding energies. This can be rationalized as the effect of the exclusive presence of fluorine induced $\mathrm{Ce}^{3+}$ ions in the vicinity of the oxygen ions at the surface. Naturally, the covalent interaction between $\mathrm{Ce}^{3+}$ and those oxygen ions is reduced in comparison to bonding with $\mathrm{Ce}^{4+}$ ions. ${ }^{37}$ One might jump to the conclusion that this effect and the contracted 

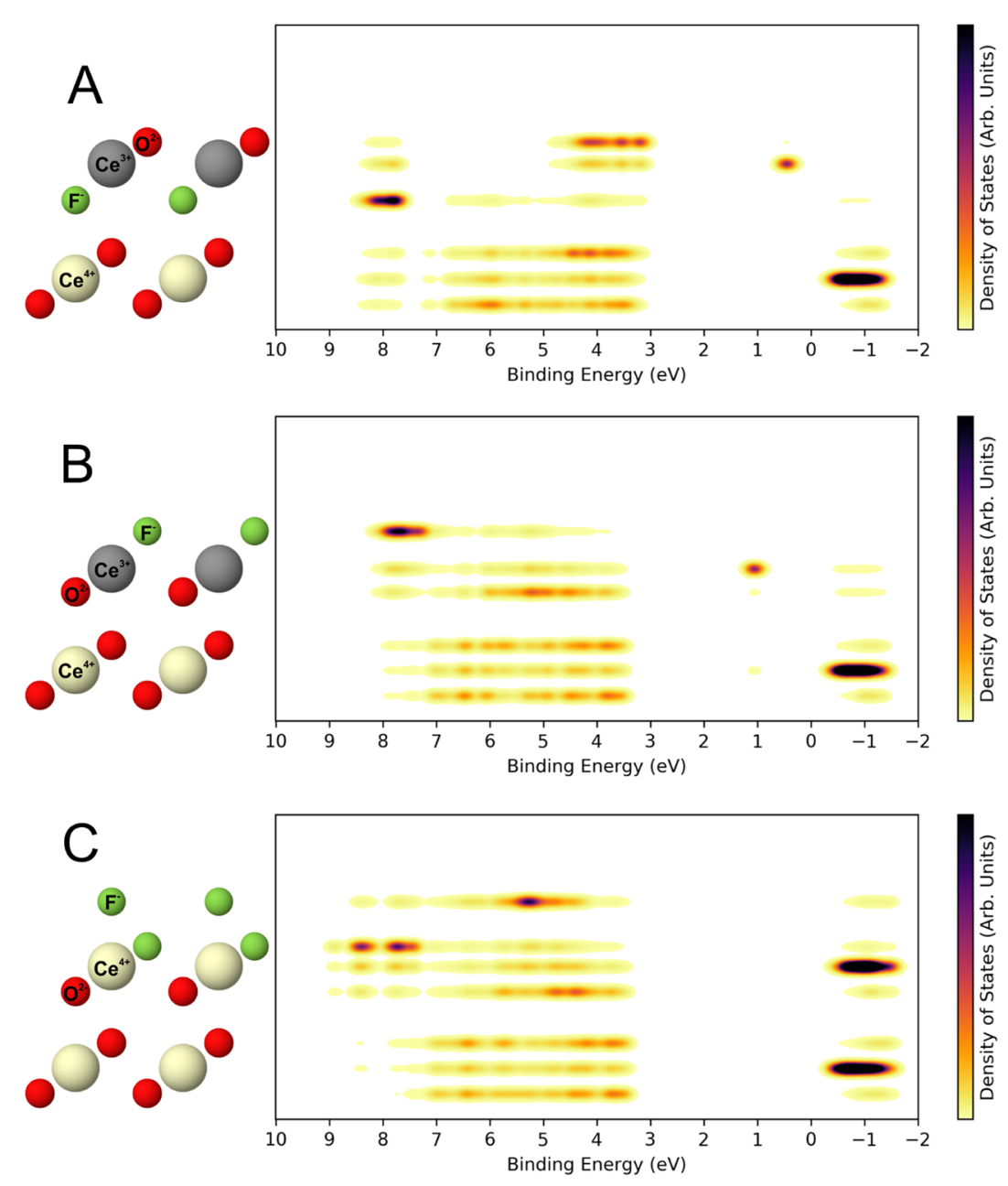

FIG. 2. Calculated projected densities of states (PDOS) of the top six atomic layers of ceria(111) slabs with fluorine dopants in (a) the subsurface layer, (b) the surface layer, and (c) the surface layer and adsorbed on top. The horizontal axis indicates the energy, while the vertical axis indicates the height of the atomic layer in the slab shown to the left of each plot; the value of the PDOS itself is indicated by color such that the darker the color, the greater the value of the PDOS. As indicated, in the atomic structures, $\mathrm{Ce}^{4+}$ and $\mathrm{Ce}^{3+}$ ions are represented by large cream and grey colored spheres, while oxygen and fluoride ions are represented by red and green colored spheres, respectively. See text for further details. states of oxygen ions at the surface in Fig. 2(a) are the origin of the new states at the top of the $\mathrm{O} 2 \mathrm{p}$ band in the measured photoemission spectra of $\mathrm{Ce}_{0.55}^{4+} \mathrm{Ce}_{0.45}^{3+} \mathrm{O}_{1.37}^{2-} \mathrm{F}_{0.80}^{-}$[see Fig. 1(h)]. However, there are several reasons why such a conclusion would be inconsistent with the results presented here. First, as previously mentioned, the subsurface position for fluorine is energetically less favorable than the surface position. ${ }^{19,23}$ Second, we do not observe the gap between the $\mathrm{F} 2 \mathrm{p}$ and $\mathrm{O} 2 \mathrm{p}$ states in the experimental spectrum. Finally, and most importantly, the resonant photoemission process at the $\mathrm{Ce} 4 \mathrm{~d} \rightarrow 4$ f photoabsorption threshold of the $\mathrm{Ce}^{3+}$ ions bonded to the surface oxygen ions would involve solely the $\mathrm{f}-\mathrm{f}$ interaction decay channel, with negligible contributions from any surrounding 2 p electrons. ${ }^{37}$ This means that the structure we are looking for must have $\mathrm{Ce}^{4+}$ ions in the vicinity of any such electrons that would give rise to the new states.

Interestingly, our recent theoretical work on fluorine impurities at $\mathrm{CeO}_{2}(111)$ suggests a candidate that would satisfy this condition. ${ }^{23}$ The structure consists of a fluoride ion in the surface, substituting for a lattice oxygen ion, with an additional fluoride ion adsorbed on top of a neighboring cerium site [see Fig. 2(c)]. The presence of two fluoride ions per missing surface oxygen ion leaves no excess electron to reduce the neighboring cerium ion, which therefore maintains its nominal $4+$ charge state. The calculated density of states for this configuration is shown on the right-hand side of Fig. 2(c). The $2 p$ states of fluorine are conjoined with the $\mathrm{O} 2 \mathrm{p}$ states, as was observed in the experimental RPES data [see Fig. 1(h)]. Moreover, we see that the $2 \mathrm{p}$ states of the adsorbed $\mathrm{F}^{-}$ion possess markedly lower binding energies than those of the substituent, consistent with their low co-ordination, to the extent that they appear at $\sim 5 \mathrm{eV}$. Their shoulder extends even to $\sim 4 \mathrm{eV}$, which is basically the top of the $\mathrm{O} 2 \mathrm{p}$ band. A concurrent increase in density of states is also visible on the surface cerium ions, which suggests a certain degree of covalent bonding between the adsorbed $\mathrm{F}^{-}$and $\mathrm{Ce}^{4+}$. We put this configuration forward as the origin of the new states observed in the experimental spectrum of the $\mathrm{Ce}_{0.55}^{4+} \mathrm{Ce}_{0.45}^{3+} \mathrm{O}_{1.37}^{2-} \mathrm{F}_{0.80}^{-}$ sample.

The proposed configuration captures all of the distinct experimental observations regarding the emergent states, namely, the simultaneous presence of both $\mathrm{F}^{-}$and $\mathrm{Ce}^{4+}$ ions and covalent interaction between their respective valence states. The covalent interaction, in the theoretical framework, is revealed by the presence of some Ce $4 \mathrm{f}$ character on fluoride ions and $\mathrm{F} 2 \mathrm{p}$ character on 
cerium ions, which is consistent with the current cerium-anion bonding picture. ${ }^{26,37}$ For a straightforward visualization, we invite the reader to compare the unoccupied states below $2 \mathrm{eV}$ in Figs. 2(b) and 2(c), where the Ce $4 \mathrm{f}$ states are clearly not present on fluoride ions in the former case. The experimental observation is less direct, but similarly conclusive. In the resonant photoemission process giving rise to the new states [see the black circle in Fig. 1(h)], a Ce $4 \mathrm{~d}$ core-hole is screened via a covalent interaction where F $2 p$ electrons move toward and partially localize on the perturbed $\mathrm{Ce}^{4+}$ ion. $^{25,26,37}$ This so-called closed-shell screening is representative of covalent mixing between the participating states. ${ }^{54}$ Considering the generally Coulombic interactions of fluoride ions, the revealed covalent mixing is surprising. Altogether, the character of the newly discovered fluorine states is highly relevant to the properties of ceria, especially in the light of the recent highlights of the role of $2 p$ anion states in the chemistry of reducible metal oxides. ${ }^{15} \mathrm{We}$ note that the precise quantification of the observed covalent mixing remains an outstanding question, the complexity of which extends well beyond the scope of the current contribution. The complexity lies in the fact that the correlated nature of electrons in ceria ${ }^{24}$ leads to strong multiplet splitting effects in the final states ${ }^{25}$ accessible by spectroscopic methods that could be used for the purpose (such as the resonant photoemission used in this study or X-ray absorption spectroscopy ${ }^{55}$ ), preventing straightforward quantification.

\section{CONCLUSION}

Our combined experimental and theoretical investigation reveals the flexibility that fluorine doping offers for modifying the electronic structure of ceria. The results show that the simultaneous presence of fluoride ions and $\mathrm{Ce}^{4+}$ leads to the emergence of new states below, within, and above the valence band. We demonstrate that the new states originate from fluoride in various near surface layers and identify a distinct configuration consisting of two fluoride ions, one substitutional and one adsorbed, charge compensating an oxygen vacancy. The charge compensation has a marked effect on the energy of the corresponding F 2p states that are found to be covalently interacting with the $\mathrm{Ce}^{4+}$ ions. Furthermore, the results suggest that an interplay between the concentration of oxygen vacancies and fluorine dopants influences the depth distribution of the latter. The F 2 p states shift toward the Fermi level the closer to the surface the fluoride dopants are. Both findings reveal effects of fluorine incorporation that extend beyond the direct increase of f-electron density, and allow for tailoring of $2 p$ mediated interactions above, within, and below the energy range spanned by the $\mathrm{O}$ $2 \mathrm{p}$ band. The results illustrate the strong influence that fluorine doping, be it through contamination or rational design, can have on the valence band electronic structure of ceria.

\section{ACKNOWLEDGMENTS}

M.K., T.D., K.V., and V.N. were supported by the Czech Science Foundation (Grant No. GAČR 15-06759S) and the Grant Agency of Charles University (Grant Nos. GAUK 897316 and GAUK 472216). S.D.S. was funded by the US Department of Energy Office of Science and Office of Basic Energy Sciences under Contract No. DE-SC0012704. M.J.W., J.K., and K.H. were supported by the Swedish Research Council (VR) and the national Swedish e-science initiative eSSENSE. The calculations were performed on resources provided by the Swedish National Infrastructure for Computing (SNIC) at NSC. We thank Klára Beranová as well as other staff of the Materials Science beamline at Elettra Sincrotrone Trieste for support during the beam time. We are also grateful to Jiří Libra for providing the KolXPD software for processing the photoemission data (www.kolibrik.net).

\section{REFERENCES}

${ }^{1}$ D. A. Andersson, S. I. Simak, N. V. Skorodumova, I. A. Abrikosov, and B. Johansson, "Optimization of ionic conductivity in doped ceria," Proc. Natl. Acad. Sci. U. S. A. 103, 3518-3521 (2006).

${ }^{2}$ C. T. Campbell, "Catalyst-support interactions: Electronic perturbations," Nat. Chem. 4, 597-598 (2012).

${ }^{3}$ A. K. Lucid, P. R. L. Keating, J. P. Allen, and G. W. Watson, "Structure and reducibility of $\mathrm{CeO}_{2}$ doped with trivalent cations," J. Phys. Chem. C 120, 23430-23440 (2016).

${ }^{4}$ J. Wu, Y.-M. Wang, A. Drljevic, V. Rauniyar, R. J. Phipps, and F. D. Toste, "A combination of directing groups and chiral anion phase-transfer catalysis for enantioselective fluorination of alkenes," Proc. Natl. Acad. Sci. U. S. A. 110, 13729-13733 (2013).

${ }^{5}$ R. J. Phipps, G. L. Hamilton, and F. D. Toste, “The progression of chiral anions from concepts to applications in asymmetric catalysis," Nat. Chem. 4, 603-614 (2012).

${ }^{6}$ T. Montini, M. Melchionna, M. Monai, and P. Fornasiero, "Fundamentals and catalytic applications of $\mathrm{CeO}_{2}$-based materials," Chem. Rev. 116, 5987-6041 (2016).

${ }^{7}$ D. R. Mullins, “The surface chemistry of cerium oxide," Surf. Sci. Rep. 70, 42-85 (2015).

${ }^{8}$ A. Holmgren, B. Andersson, and D. Duprez, "Interactions of CO with Pt/ceria catalysts," Appl. Catal. B Environ. 22, 215-230 (1999).

${ }^{9}$ J. Zarraga-Colina, R. M. Nix, and H. Weiss, "Growth, structure, and stability of ceria films on $\mathrm{Si}(111)$ and the application of $\mathrm{CaF}_{2}$ buffer layers," J. Phys. Chem. B 109, 10978-10985 (2005).

${ }^{10}$ A. P. Amrute, C. Mondelli, M. Moser, G. Novell-Leruth, N. López, D. Rosenthal, R. Farra, M. E. Schuster, D. Teschner, T. Schmidt et al., "Performance, structure, and mechanism of $\mathrm{CeO}_{2}$ in HCL oxidation to $\mathrm{Cl}_{2}$," J. Catal. 286, 287-297 (2012).

${ }^{11}$ H. H. Pieper, C. Derks, M. H. Zoellner, R. Olbrich, L. Tröger, T. Schroeder, M. Neumann, and M. Reichling, "Morphology and nanostructure of $\mathrm{CeO}_{2}(111)$ surfaces of single crystals and $\mathrm{Si}(111)$ supported ceria films," Phys. Chem. Chem. Phys. 14, 15361-15368 (2012)

${ }^{12}$ R. Asahi, T. Morikawa, T. Ohwaki, K. Aoki, and Y. Taga, "Visible-light photocatalysis in nitrogen-doped titanium oxides," Science 293, 269-271 (2001).

${ }^{13}$ S. Ahmad, K. Gopalaiah, S. N. Chandrudu, and R. Nagarajan, "Anion (fluoride)doped ceria nanocrystals: Synthesis, characterization, and its catalytic application to oxidative coupling of benzylamines," Inorg. Chem. 53, 2030-2039 (2014).

${ }^{14}$ R. Zhang, Q. Zhong, W. Zhao, L. Yu, and H. Qu, "Promotional effect of fluorine on the selective catalytic reduction of $\mathrm{NO}$ with $\mathrm{NH}_{3}$ over $\mathrm{CeO}_{2}-\mathrm{TiO}_{2}$ catalyst at low temperature," Appl. Surf. Sci. 289, 237-244 (2014).

${ }^{15}$ D. N. Mueller, M. L. Machala, H. Bluhm, and W. C. Chueh, "Redox activity of surface oxygen anions in oxygen-deficient perovskite oxides during electrochemical reactions," Nat. Commun. 6, 6097 (2015).

${ }^{16}$ W. Finkelnburg and A. Stein, "Cerium oxyfluoride and its lattice structure," J. Chem. Phys. 18, 1296 (1950).

${ }^{17}$ A. I. Popov and G. E. Knudson, "Preparation and properties of the rare earth fluorides and oxyfluorides,” J. Am. Chem. Soc. 76, 3921-3922 (1954).

${ }^{18}$ N. Baenziger, J. Holden, G. Knudson, and A. Popov, "Unit cell dimensions of some rare earth oxyfluorides,” J. Am. Chem. Soc. 76, 4734-4735 (1954).

${ }^{19}$ J. Kullgren, M. J. Wolf, C. W. M. Castleton, P. Mitev, W. J. Briels, and K. Hermansson, "Oxygen vacancies versus fluorine at $\mathrm{CeO}_{2}(111)$ : A case of mistaken identity?,” Phys. Rev. Lett. 112, 156102 (2014). 
${ }^{20} \mathrm{M}$. Takashima, S. Fukami, Y. Nosaka, and T. Unishi, "Reaction between rare earth oxides and elemental fluorine. II. Kinetics of the fluorination of cerium dioxide," J. Fluorine Chem. 57, 131-138 (1992).

${ }^{21}$ R. Fiala, M. Vaclavů, A. Rednyk, I. Khalakhan, M. Vorokhta, J. Lavková, V. Potin, I. Matolínová, and V. Matolín, "Pt-CeO ${ }_{x}$ thin film catalysts for PEMFC," Catal. Today 240, 236-241 (2015).

${ }^{22}$ M. Kettner, K. Ševčíková, P. Homola, V. Matolín, and V. Nehasil, "Influence of the $\mathrm{Ce}-\mathrm{F}$ interaction on cerium photoelectron spectra in $\mathrm{CeO}_{x} \mathrm{~F}_{y}$ layers," Chem. Phys. Lett. 639, 126-130 (2015).

${ }^{23} \mathrm{M}$. J. Wolf, J. Kullgren, P. Broqvist, and K. Hermansson, "Fluorine impurities at $\mathrm{CeO}_{2}$ (111): Effects on oxygen vacancy formation, molecular adsorption, and surface re-oxidation," J. Chem. Phys. 146, 044703 (2017).

${ }^{24}$ C. J. Nelin, P. S. Bagus, E. S. Ilton, S. A. Chambers, H. Kuhlenbeck, and H.-J. Freund, "Relationships between complex core level spectra and materials properties," Int. J. Quantum Chem. 110, 2752-2764 (2010).

${ }^{25}$ P. S. Bagus, C. J. Nelin, Y. Al-Salik, E. S. Ilton, and H. Idriss, "Multiplet splitting for the XPS of heavy elements: Dependence on oxidation state," Surf. Sci. 643, 142-149 (2016).

${ }^{26}$ P. S. Bagus, C. J. Nelin, D. A. Hrovat, and E. S. Ilton, "Covalent bonding in heavy metal oxides," J. Chem. Phys. 146, 134706 (2017).

${ }^{27}$ J. Paier, C. Penschke, and J. Sauer, "Oxygen defects and surface chemistry of ceria: Quantum chemical studies compared to experiment," Chem. Rev. 113, 3949-3985 (2013).

${ }^{28}$ M. Kettner, K. Ševčíková, T. Duchoň, P. Kúš, Z. Rafaj, and V. Nehasil, "Morphology and $\mathrm{CO}$ oxidation reactions on anion doped $\mathrm{CeO}_{X} \mathrm{~F}_{Y} / \mathrm{Rh}(111)$ and $\mathrm{CeO}_{X} / \mathrm{Rh}(111)$ inverse catalysts," J. Phys. Chem. C 120, 26782-26792 (2016).

${ }^{29} \mathrm{R}$. Gillen, S. J. Clark, and J. Robertson, "Nature of the electronic band gap in lanthanide oxides," Phys. Rev. B 87, 125116 (2013).

${ }^{30}$ C. Balaji Gopal, M. García-Melchor, S. C. Lee, Y. Shi, A. Shavorskiy, M. Monti, Z. Guan, R. Sinclair, H. Bluhm, A. Vojvodic, and W. C. Chueh, "Equilibrium oxygen storage capacity of ultrathin $\mathrm{CeO}_{2}-\delta$ depends non-monotonically on large biaxial strain," Nat. Commun. 8, 15360 (2017).

${ }^{31}$ D. R. Mullins, P. M. Albrecht, T.-l. Chen, F. C. Calaza, M. D. Biegalski, H. M. Christen, and S. H. Overbury, "Water dissociation on $\mathrm{CeO}_{2}(100)$ and $\mathrm{CeO}_{2}$ (111) thin films," J. Phys. Chem. C 116, 19419-19428 (2012).

${ }^{32}$ M. Casaletto, R. Zanoni, M. Carbone, M. Piancastelli, L. Aballe, K. Weiss, and K. Horn, "High-resolution photoemission study of ethanol on $\mathrm{Si}(100) 2 \times 1$," Surf. Sci. 447, 237-244 (2000).

${ }^{33}$ V. Matolín, J. Libra, M. Škoda, N. Tsud, K. Prince, and T. Skála, "Methanol adsorption on a $\mathrm{CeO}_{2}(111) / \mathrm{Cu}(111)$ thin film model catalyst," Surf. Sci. 603, 1087-1092 (2009).

${ }^{34}$ A. Neitzel, A. Figueroba, Y. Lykhach, T. Skála, M. Vorokhta, N. Tsud, S. Mehl, K. Ševčíková, K. C. Prince, K. M. Neyman, V. Matolín, and J. Libuda, "Atomically dispersed Pd, Ni, and Pt species in ceria-based catalysts: Principal differences in stability and reactivity," J. Phys. Chem. C 120, 9852-9862 (2016).

${ }^{35}$ J. Graciani, K. Mudiyanselage, F. Xu, a. E. Baber, J. Evans, S. D. Senanayake, D. J. Stacchiola, P. Liu, J. Hrbek, J. F. Sanz, and J. A. Rodriguez, "Highly active copper-ceria and copper-ceria-titania catalysts for methanol synthesis from $\mathrm{CO}_{2}$," Science 345, 546-550 (2014)

${ }^{36}$ M. N. Grisolia, J. Varignon, G. Sanchez-Santolino, A. Arora, S. Valencia, M. Varela, R. Abrudan, E. Weschke, E. Schierle, J. E. Rault, J.-P. Rueff, A. Barthélémy, J. Santamaria, and M. Bibes, "Hybridization-controlled charge transfer and induced magnetism at correlated oxide interfaces," Nat. Phys. 12, 484-492 (2016).
${ }^{37}$ T. Duchoň, M. Aulická, E. F. Schwier, H. Iwasawa, C. Zhao, Y. Xu, K. Veltruská, K. Shimada, and V. Matolín, "Covalent versus localized nature of $4 f$ electrons in ceria: Resonant angle-resolved photoemission spectroscopy and density functional theory," Phys. Rev. B 95, 165124 (2017).

${ }^{38}$ H. Shinotsuka, S. Tanuma, C. J. Powell, and D. R. Penn, "Calculations of electron inelastic mean free paths. X. Data for 41 elemental solids over the $50 \mathrm{eV}$ to $200 \mathrm{keV}$ range with the relativistic full Penn algorithm," Surf. Interface Anal. 47, 871-888 (2015).

${ }^{39}$ J. Höcker, J.-O. Krisponeit, T. Schmidt, J. Falta, and J. I. Flege, "The cubic-tohexagonal phase transition of cerium oxide particles: Dynamics and structure," Nanoscale 9, 9352-9358 (2017).

${ }^{40}$ C. D. Wagner, D. Briggs, and M. Seah, Practical Surface Analysis, 2nd ed. (J. Wiley and Sons, 1990), p. Apendix 6.

${ }^{41}$ P. E. Blöchl, "Projector augmented-wave method," Phys. Rev. B 50, 17953 (1994).

${ }^{42}$ G. Kresse and J. Hafner, “A $b$ initio molecular dynamics for liquid metals," Phys. Rev. B 47, 558 (1993).

${ }^{43}$ G. Kresse and J. Furthmüller, "Efficiency of $a b$-initio total energy calculations for metals and semiconductors using a plane-wave basis set," Comput. Mater. Sci. 6, 15-50 (1996)

${ }^{44}$ G. Kresse and J. Furthmüller, "Efficient iterative schemes for $a b$ initio totalenergy calculations using a plane-wave basis set,” Phys. Rev. B 54, 11169 (1996).

${ }^{45}$ G. Kresse and D. Joubert, "From ultrasoft pseudopotentials to the projector augmented-wave method,” Phys. Rev. B 59, 1758 (1999).

${ }^{46}$ H. J. Monkhorst and J. D. Pack, "Special points for Brillouin-zone integrations," Phys. Rev. B 13, 5188 (1976).

${ }^{47}$ J. Heyd, G. E. Scuseria, and M. Ernzerhof, "Hybrid functionals based on a screened Coulomb potential," J. Chem. Phys. 118, 8207-8215 (2003).

${ }^{48}$ J. Heyd, G. E. Scuseria, and M. Ernzerhof, "Erratum: 'Hybrid functionals based on a screened coulomb potential' [J. Chem. Phys. 118, 8207 (2003)],” J. Chem. Phys. 124, 219906 (2006).

${ }^{49}$ J. L. Da Silva, M. V. Ganduglia-Pirovano, J. Sauer, V. Bayer, and G. Kresse, "Hybrid functionals applied to rare-earth oxides: The example of ceria," Phys. Rev. B 75, 045121 (2007).

${ }^{50}$ D. Du, M. J. Wolf, K. Hermansson, and P. Broqvist, "Screened hybrid functionals applied to ceria: Effect of Fock exchange," Phys. Rev. B 97, 235203 (2018).

${ }^{51}$ M. Matsumoto, K. Soda, K. Ichikawa, S. Tanaka, Y. Taguchi, K. Jouda, O. Aita, Y. Tezuka, and S. Shin, "Resonant photoemission study of $\mathrm{CeO}_{2}$," Phys. Rev. B 50, 11340-11346 (1994).

${ }^{\mathbf{5 2}} \mathrm{U}$. Fano, "Effects of configuration interaction on intensities and phase shifts," Phys. Rev. 124, 1866-1878 (1961).

${ }^{53}$ T. Duchoň, F. Dvořák, M. Aulická, V. Stetsovych, M. Vorokhta, D. Mazur, K. Veltruská, T. Skála, J. Mysliveček, I. Matolínová et al., "Ordered phases of reduced ceria as epitaxial films on $\mathrm{Cu}(111)$," J. Phys. Chem. C 118, 357-365 (2014).

${ }^{54}$ P. S. Bagus and C. J. Nelin, "Covalent interactions in oxides," J. Electron Spectros. Relat. Phenomena 194, 37-44 (2014).

${ }^{55}$ J. Suntivich, W. T. Hong, Y. L. Lee, J. M. Rondinelli, W. Yang, J. B. Goodenough, B. Dabrowski, J. W. Freeland, and Y. Shao-Horn, "Estimating hybridization of transition metal and oxygen states in perovskites from $\mathrm{O}$ K-edge X-ray absorption spectroscopy," J. Phys. Chem. C 118, 1856-1863 (2014). 